\title{
KAJIAN SISTEM AGRIBISNIS UBI KAYU PADA KELOMPOK TANI SUNGAI SUCI DI DESA PASAR PEDATI KECAMATAN PONDOK KELAPA KABUPATEN BENGKULU TENGAH
}

\author{
Agribusiness System Assesment on Cassava Farmers Group in \\ Sungai Suci Pasar Pedati Pondok Kelapa Subdistrict \\ Central Bengkulu District
}

\author{
Yesko Crismas Siallagan, Putri Suci Asriani, dan Apri Andani \\ Jurusan Sosial Ekonomi Pertanian Fakultas Pertanian Universitas Bengkulu \\ yesko_s@yahoo.com
}

\begin{abstract}
The purpose of this study are identifying the types and the role of the subsystems of production facilities in the agribusiness system cassava managed by Farmer Group of Sungai Suci, subsystem farming analyzed in agribusiness system cassava managed by Farmers Group in Sungai Suci, analyze subsystem agroindustry in the agribusiness system managed by Farmer Group in Sungai Suci, analyze marketing subsystem in cassava agribusiness system managed by Farmers Group in Sungai Suci, identifying the types and subsystems supporting role in the system of cassava agribusiness managed by Farmer Group in Sungai Suci.The determination location methode is purposive. Respondents determination in this study using census methode in the Sungai Suci Farmer Group. Data collected was primary data and secondary data. Data were analyzed using descriptive analysis, farming analysis, agroindustry analysis, and marketing channels analysis. The result showed that Cassava farm incomes on average per ha in one growing season is the real income is $R p$ 18.681.033, unriil revenue is $R p$ 12.626.045 Cassava agroindustry every month have the income namely: from the farmers directly to agroindustrial Cassava Farmers Sungai Suci and from farmers to collectors village level and then to the consumer artisans cassava processing while the processed agroindustrial cassava there are three grooves, namely: mocaf flour processing Rp 1.707.500,- Rengginang Rp.1.650.693-, and Rp.2.513.400 chips. Flow marketing of cassava includes two strands, namely: from the farmers directly to agroindustrial Cassava Farmers Sungai Suci and from farmers to collectors village level and then to the consumer artisans cassava processing while the processed agroindustry cassava there are three grooves, namely: from farmer groups to consumers artisan cakes and households, the second from farmer groups to household consumers, and a third of farmers' groups to a merchant retailers and then to consumers. Subsystems supporting role in agribusiness systems of cassava in the Sungai Suci Farmers Group is Women Farmers Sungai Suci and the Government cooperation.
\end{abstract}

Keywords: agribusiness, cassava, farmer group 


\section{PENDAHULUAN}

Salah satu komoditas pertanian yang perlu ditata sistem agribisnisnya adalah ubi kayu, karena ubi kayu merupakan komoditas tanaman pangan yang penting sebagai penghasil sumber bahan pangan karbohidrat dan bahan baku industri makanan, kimia dan pakan ternak. Komoditi ubi kayu juga merupakan salah satu komoditas tanaman pangan yang menghasilkan devisa negara melalui ekspor dalam bentuk olahan dari ubi kayu, maka dari itu ubi kayu merupakan aset berharga dan perlu dijaga kelestariannya. (Muizah, dkk, 2013).

Untuk membuat suatu sistem yang baik dalam sitem agribisnis ubi kayu harus dimulai dari subsistem pertama yaitu subsistem sarana produksi. Sarana produksi dalam pertanian terdiri dari alat-alat pertanian, pupuk dan pestisida, dimana alat-alat pertanian untuk mengelola lahan dan tanaman digunakan alat-alat seperti cangkul, parang babat, arit dan traktor (Suratiyah, 2008). Selanjutnya subsistem usahatani merupakan subsistem dimana petani membudidayakan ubi kayu dengan mengalokasikan sumberdaya yang ada secara efektif dan efisien untuk menghasilkan pendapatan yang maksimal. Dalam satu sistem setiap subsistem saling berhubungan, maka output yang dihasilkan di subsistem usahatani akan menjadi input di subsistem agroindustri. Hal ini juga baik dilakukan dikarenakan sifat produk pertanian yang tidak tahan lama maka peran subsistem agroindustri sangat diperlukan. (Thamrin, dkk, 2013).

Sistem agribisnis ubi kayu dapat dijumpai di Bengkulu, khususnya Desa Pasar Pedati Kecamatan Pondok Kelapa Kabupaten Bengkulu Tengah yang dikelola oleh sekelompok petani dengan nama kelompok "Kelompok Tani Sungai Suci". Kelompok Tani sungai suci berdiri tahun 2008 dengan anggota 15 orang. Sejak berdiri Kelompok Tani ini bergerak di bidang agribisnis ubi kayu. Kelompok Tani Sungai Suci menanam atau bertani ubi kayu yang kemudian hasil panen ubi kayu tersebut diolah menjadi berbagai produk olahan dari ubi kayu. Adapun berbagai olahan dari ubi kayu yang dihasilkan kelompok ini adalah: tepung Mocaf, Rengginang, dan keripik. Hasil olahan tersebut kemudian dipasarkan dengan cara pembeli datang langsung ke lokasi Kelompok Tani Sungai Suci. Kegiatan produktif untuk menjalankan sistem agribisnis tersebut memerlukan subsistem-subsistem yang berperan dengan baik didalam sistem agribisnis ubi kayu tersebut.

Maka dari itu peneliti tertarik untuk melakukan penelitian dengan judul "Kajian Sistem Agribisnis Ubi Kayu Pada Kelompok Tani Sungai Suci di Desa Pasar Pedati Kecamatan Pondok Kelapa Kabupaten Bengkulu Tengah". Berdasarkan latar belakang di atas maka tujuan dalam penelitian ini dapat dirumuskan untuk (a) Mengidentifikasi jenis-jenis dan peranan subsistem sarana produksi dalam (b) sistem agribisnis ubi kayu yang dikelola oleh Kelompok Tani Sungai Suci, (c) menganalisis Subsistem usahatani dalam sistem agribisnis ubi kayu yang dikelola oleh Kelompok Tani Sungai Suci, (d) menganalisis subsistem agroindustri dalam sistem agribisnis ubi kayu yang 
dikelola oleh Kelompok Tani Sungai Suci, mengidentifikasi subsistem pemasaran dalam sistem agribisnis ubi kayu yang dikelola oleh Kelompok Tani Sungai Suci, dan (e) mengidentifikasi jenis-jenis dan peranan subsistem penunjang dalam sistem agribisnis ubi kayu yang dikelola oleh Kelompok Tani Sungai Suci.

\section{METODE PENELITIAN}

\section{Penentuan Lokasi}

Penentuan lokasi penelitian dilakukan dengan secara sengaja (purposive) yaitu di Desa Pasar Pedati Kecamatan Pondok Kelapa Kabupaten Bengkulu Tengah, dengan pertimbangan bahwa di daerah tersebut terdapat agribisnis ubi kayu yang dikelola oleh Kelompok Tani sungai suci. Penelitian dilakukan pada bulan Maret-April 2016.

\section{Penentuan Responden}

Responden yang digunakan untuk mengidentifikasi dan menganalisis subsistem sarana produksi dan subsistem usahatani adalah semua anggota Kelompok Tani Sungai Suci yang melakukan usahatani ubi kayu yaitu Sebanyak 14 orang metode ini dilakukan dengan metode sensus. Sampel untuk analisis usaha adalah usaha pengolahan ubi kayu Kelompok Tani Sungai Suci. Untuk menentukan responden analisis saluran pemasaran dilakukan dengan metode Snow ball sampling. Selanjutnya untuk responden mengidentifikasi subsistem penunjang adalah lembaga yang menunjang langsung sistem agribisnis ubi kayu pada Kelompok Tani Sungai Suci

\section{Pengumpulan Data}

Data yang digunakan dalam penelitian ini adalah data primer dan data sekunder. Data primer diperoleh dengan melakukan, wawancara dan penyebaran kuesioner kepada responden. Data sekunder didapat dari penelusuran berupa dokumen dari instansi yang terkait (BPS, Dinas Pertanian beserta instansi lainnya), dan berbagai media cetak serta sumber dari buku dan literatur yang relevan dengan topik penelitian.

\section{Analisis Data}

\section{Mengkaji subsistem sarana produksi}

Subsistem sarana produksi dikaji secara deskriptif yaitu bagaimana peranan subsistem sarana produksi terhadap sistem agribisnis ubi kayu yang dikelola kelompok tani Sungai Suci. Dalam menjelaskan subsistem sarana produksi akan dijelaskan tentang sarana produksi (saprodi) ubi kayu, yang digunakan untuk memproduksi ubi kayu. Serta dijelaskan bagaimana peranan dan jenis-jenis sarana produksi yang ada pada sistem agribisnis ubi kayu yang dikelola oleh Kelompok Tani sungai suci. 
ISSN: 1412-8837

\section{Mengkaji subsistem usahatani}

Analisis biaya usahatani ubi kayu

Total biaya merupakan biaya dari penjumlahan biaya tetap dan biaya tidak tetap, yang digunakan bersama-sama dalam proses produksi. Secara sistematis dapat ditulis sebagai berikut :

$\mathrm{TC}=\mathrm{FC}+\mathrm{VC}$ (Soekartawi, 2002)

Analisis Penerimaan usahatani ubi kayu

Penerimaan diperoleh dari hasil perkalian jumlah produksi dengan harga jual ubi kayu yang dihasilkan. Secara sistematis dapat dirumuskan sebagai berikut :

TR $=$ Y x Py (Soekartawi, 2002)

Analisis pendapatan usahatani ubi kayu

Analisis pendapatan yang diperoleh dalam satu musim dapat dihitung dengan analisis melalui pendekatan pendapatan, yaitu :

$\mathrm{Pd}=\mathrm{TR}-\mathrm{TC}$ (Soekartawi, 2002)

\section{Mengkaji subsistem agroindustri}

Analisisi Usaha

Untuk menganalisis keuntungan agroindustri ubi kayu dilakukan analisis perhitungan laporan rugi laba. Namun sebelumnya dilakukan analisis laporan harga pokok produksi menurut Soemarso (1999).

Efisiensi usaha

B/C Ratio

Menurut Rahardi dan Hartono (2003) Analisis keuntungan dan biaya (B/C Ratio) adalah perbandingan antara tingkat keuntungan yang diperoleh dengan total biaya yang dikeluarkan. Suatu usaha dikatakan efisien dan memberikan manfaat apabila nilai B/C lebih besar dari nol. Semakin besar nilai B/C maka semakin besar nilai manfaat yang akan diperoleh dari usaha tersebut. Secara matematis dapat dirumuskan sebagai berikut:

$$
B / C=\frac{\text { Total Keutungan }}{\text { Harga Pokok Produksi }}
$$

Break Even Point (BEP)

Menurut Wiryanta (2002) BEP merupakan titik impas. Dari nilai BEP diketahui pada tingkat produksi dan harga berapa suatu usaha tidak memberikan keuntungan dan tidak pula mengalami kerugian.

$$
\begin{aligned}
& \text { BEP Volume }=\frac{\text { Harga Pokok Produksi }}{\text { Harga Penjualan }}(\mathrm{Kg} / \text { Bulan }) \\
& \text { BEP Harga }=\frac{\text { Harga Pokok Produksi }}{\text { Total Produksi }}(\mathrm{Rp} / \text { Unit })
\end{aligned}
$$

\section{Mengkaji subsistem pemasaran}

Subsistem pemasaran akan dikaji Alur pemasaran hasil olahan ubi kayu yaitu berupa tepung mocaf, rengginang, dan keripik singkong dengan cara menggunakan metode penelusuran pemasaran hasil olahan ubi kayu dari titik

226 | Yesko Crismas S., Putri Suci A., dan Apri A., Kajian Sistem Agribisnis... 
produsen sampai kepada ke konsumen. Alur pemasaran tersebut dijadikan dasar dalam menggambarkan pola saluran pemasaran.

\section{Mengkaji subsistem penunjang}

Subsistem penunjang akan dilakukan dengan mengidentifikasi lembagalembaga yang berperan dalam mendukung sistem agribisnis ubi kayu yang dikelola oleh Kelompok Tani sungai suci.

\section{HASIL DAN PEMBAHASAN}

\section{Subsistem Sarana Produksi Ubi Kayu Pada Kelompok Tani Sungai Suci}

Subsistem sarana produksi ubi kayu pada Kelompok Tani Sungai Suci adalah unit usaha penyediaan bibit, unit usaha penyediaan pupuk, unit usaha penyediaan mesin pertanian dan unit usaha penyediaan tenaga kerja.

\section{Subsistem Usahatani Ubi Kayu Pada Kelompok Tani Sungai Suci}

Biaya Usahatani Ubi Kayu Pada Kelompok Tani Sungai Suci

Biaya yang digunakan dalam subsistem usahatani ubi kayu pada Kelompok Tani Sungai Suci ada dua jenis, yaitu biaya variabel dan biaya tetap. Untuk mengetahui rata-rata biaya yang dikeluarkan petani ubi kayu anggota Kelompok Tani Sungai Suci per Ha dapat dilihat pada tabel berikut ini:

Tabel 1. Rata-rata Biaya/Ha/MT yang Dikeluarkan Pelaku Subsistem Usahatani Ubi Kayu pada Kelompok Tani Sungai Suci

\begin{tabular}{lrrrr}
\hline \multirow{2}{*}{ Jenis Biaya } & \multicolumn{3}{c}{ Biaya Rill } & \multicolumn{2}{c}{ Biaya Unrill } \\
\cline { 2 - 5 } & Nilai (Rp) & $(\%)$ & Nilai (Rp) & $(\%)$ \\
\hline Biaya Variabel & & & & \\
$\quad$ Biaya Bibit & 36.000 & 1,21 & 47.049 & 0,52 \\
Biaya Pupuk & & & & \\
$\quad$ Urea & 79.520 & 2,67 & 79.520 & 0,88 \\
TSP & 87.502 & 2,94 & 87.502 & 0,97 \\
KCL & 83.586 & 2,81 & 83.586 & 0,93 \\
Biaya Pestisida & & & & \\
$\quad$ Kleen Up & 142.255 & 4,78 & 142.255 & 1,58 \\
$\quad$ Round Up & 104.745 & 3,63 & 104.745 & 1,17 \\
$\quad$ Gramoxon & 73.750 & 3,52 & 73.750 & 0,82 \\
$\quad$ Decis & 11.286 & 0,37 & 11.286 & 0,12 \\
Biaya Tenaga Kerja Dalam Keluarga & 0 & & 2.274 .238 & 25,41 \\
$\quad$ Biaya Tenaga Kerja Luar Keluarga & 2.241 .334 & 75,42 & 2.241 .333 & 25,04 \\
Biaya Tetap & & 2,03 & & \\
Biaya Penyusutan Alat & 60.500 & 1,97 & 60.500 & 0,67 \\
Biaya Pajak/sewa & 58.667 & & 3.750 .932 & 41,91 \\
\hline$\quad$ Total biaya & 2.971 .573 & 100 & 8.949 .125 & 100 \\
\hline
\end{tabular}

Sumber: Data primer diolah, 2016 
Biaya yang dikeluarkan untuk usahatani ubi kayu pada Kelompok Tani Sungai Suci adalah Biaya Variabel yang terdiri dari biaya bibit, biaya pupuk, biaya pestisida, biaya tenaga kerja dalam keluarga, biaya tenaga kerja luar keluarga dan biaya tetap yang terdiri dari biaya penyusutan dan biaya pajak/sewa.

\section{Penerimaan Subsistem Usahatani Ubi Kayu Pada Kelompok Tani Sungai Suci}

Penerimaan subsistem usahatani ubi kayu pada kelompok Tani Sungai Suci adalah jumlah produksi usahatani ubi kayu dikalikan dengan harga jual ubi kayu. Adapun rata-rata jumlah produksi ubi kayu per Ha per musim tanam yang dihasilkan Kelompok Tani Sungai Suci adalah $14.790 \mathrm{Kg}$ dengan harga jual berbeda beda, jika dijual ke kelompok tani untuk di jadikan bahan baku subsistem agroindustri maka harga jualnya menjadi Rp $1.000 / \mathrm{Kg}$ sedangkan jika dijual keluar kelompok tani harga jual ubi kayu Rp 1.500/Kg. Adapun rata-rata penerimaan anggota kelompok Tani Sungai Suci yang mengolah subsistem usahatani ubi kayu dalam satu musim tanam per $\mathrm{Ha}$ adalah sebesar $\operatorname{Rp} 21.575 .170$

\section{Pendapatan Usahatani Ubi Kayu Pada Kelompok Tani Sungai Suci}

Rata-rata pendapatan rill per Ha dalam satu musim tanam yang diterima oleh anggota Kelompok Tani Sungai Suci yang mengolah ushatani ubi kayu adalah rata-rata penerimaan $1 \mathrm{Ha}$ dalam satu musim tanam dikurangi dengan rata-rata semua biaya rill yang dikeluarkan dalam usahatani ubi kayu dalam satu musim tanam, sedangkan untuk rata-rata pendapatan unrill adalah dengan mengurangkan rata-rata biaya unrill terhadap penerimaan.

Tabel 2. Pendapatan rill dan Pendapatan Unrill Usahatani Ubi Kayu pada Kelompok Tani Sungai Suci

\begin{tabular}{lcc}
\hline \multicolumn{1}{c}{ Uraian } & Nilai rill per Ha & Nilai Unrill per Ha \\
\hline Penerimaan $(\mathrm{Rp})$ & 21.575 .170 & 21.575 .170 \\
Biaya (Rp) & 2.883 .668 & 8.949 .125 \\
Pendapatan $(\mathrm{Rp})$ & 18.681 .033 & 12.626 .045 \\
\hline
\end{tabular}

Sumber: Data primer diolah, 2016

Rata-rata penerimaan usahtani ubi kayu pada Kelompok Tani Sungai Suci per Ha dalam satu musim tanam adalah sebesar Rp 21.575.170, sedangkan rata-rata biaya rill usahatani ubi kayu pada Kelompok Tani Sungai Suci sebesar Rp 2.883.668. Sehingga rata-rata pendapatan rill per Ha dalam satu musim tanam yang diterima oleh anggota Kelompok Tani Sungai Suci adalah Rp 21.575.170 dikurang Rp 2.883.668 maka besar pendapatan rillnya adalah sebesar Rp 18.681.033. Sedangkan biaya unrill usahatani ubi kayu sebesar Rp 8.949.125, maka besarnya pendapatan unrill usahatani ubi kayu pada Kelompok Tani Sungai Suci adalah Rp 12.626.045. 


\section{Subsistem Agroindustri Ubi Kayu Pada Kelompok Tani Sungai Suci}

Analisis Usaha agroindustri Ubi Kayu Pada Kelompok tani Sungai Suci

Dalam menganalisis usaha atau keuntungan usaha agroindustri ubi kayu pada Kelompok Tani Sungai Suci dihitung dengan menggunakan perhitungan rugi/laba. Sebelum dilakukan perhitungan rugi/laba, harga pokok produksi terlebih dahulu dihitung, karena harga pokok produksi digunakan dalam perhitungan rugi/laba. Perhitungan harga pokok produksi agroindustri ubi kayu pada Kelompok Tani Sungai Suci dapat dilihat pada tabel berikut ini:

\begin{tabular}{|c|c|c|c|}
\hline Uraian & Tepung Mocaf & Rengginang & Keripik \\
\hline \multicolumn{4}{|l|}{ Persediaan bahan baku } \\
\hline Persediaan awal bahan baku (a) & 0 & 0 & 0 \\
\hline Pembelian bahan baku (b) & 1.200 .000 & 960.000 & 2.240 .000 \\
\hline Ongkos angkut bahan baku (c) & 0 & 0 & 0 \\
\hline Bahan baku yang tersedia $(\mathrm{d}=\mathrm{a}+\mathrm{b}+\mathrm{c})$ & 1.200 .000 & 960.000 & 2.240 .000 \\
\hline Persediaan akhir bahan baku (e) & 0 & 0 & 0 \\
\hline Pemakaian bahan baku $(\mathrm{f}=\mathrm{d}+\mathrm{e})$ & 1.200 .000 & 960.000 & 2.240 .000 \\
\hline Biaya bahan penolong $(\mathrm{g})$ & 10.000 & 246.000 & 0 \\
\hline Upah tenaga kerja $(\mathrm{h})$ & 1.020 .000 & 1.350 .000 & 1.800 .000 \\
\hline \multicolumn{4}{|l|}{ Biaya overhead pabrik } \\
\hline Biaya operasional (i) & 104.000 & 40.000 & 40.000 \\
\hline Biaya Penyusutan alat (j) & 85.900 & 56.507 & 24.795 \\
\hline HargaPokok Produksi $(k=f+g+h+i+j)$ & 2.419 .900 & 2.652507 & 4.040 .000 \\
\hline
\end{tabular}

Sumber: Data primer diolah, 2016

Harga pokok produksi merupakan hasil penjumlahan dari pemakaian bahan baku, biaya bahan penolong, upah tenaga kerja, dan biaya overhead pabrik. Adapun harga pokok produksi usaha agroindustri tepung mocaf pada Kelompok Tani Sungai Suci per bulan produksi adalah Rp 2.419.900. Harga pokok produksi tersebut terdiri dari biaya bahan baku Rp 1.200.000, bahan penolong sebesar $\operatorname{Rp~10.000,~upah~tenaga~kerja~} \operatorname{Rp} 1.020 .000$, dan biaya overhead pabrik yang terdiri dari Biaya operasional sebesar Rp 104.000 dan biaya penyusutan peralatan sebesar Rp. 85.900. Bahan baku yang digunakan dalam agroindustri usaha tepung mocaf yang dikelola Kelompok Tani Sungai Suci adalah ubi kayu segar yang didapatkan langsung dari anggota kelompok tani sedangkan bahan penolong menggunakan bioaktif yang didapatkan dari luar kelompok tani. Penggunaan biaya penolong relatif sedikit dalam produksi tepung mocaf. Tenaga kerja yang digunakan dalam agroindustri usaha ini menggunakan tenaga kerja dari dalam anggota kelompok tani dengan upah Rp 60.000/HOK. Biaya operasional yang dikeluarkan Kelompok Tani dalam pengolahan tepung mocaf adalah biaya bahan bakar untuk mesin penepung sedangkan biaya penyusustan alat adalah biaya penyusutan dari semua alat yang digunakan dalam agroindustri usaha tepung mocaf. 
Harga pokok produksi agroindustri usaha rengginang pada Kelompok Tani Sungai Suci per bulan produksi adalah Rp 2.652.507. Harga pokok produksi ini terdiri dari bahan baku sebesar Rp 960.000, biaya bahan penolong Rp 246.000, upah tenaga kerja Rp 1.350.000, dan biaya overhead pabrik yang terdiri dari biaya operasional sebesar $\mathrm{Rp} 40.000$ dan biaya penyusutan peralatan sebesar Rp 56.507. Biaya bahan baku untuk agroindustri usaha rengginang yang dikelola Kelompok Tani Sungai Suci menggunakan tepung mocaf hasil agroindustri kelompok Tani itu sendiri sedangkan bahan penolong menggunakan tepung sagu dan masako yang didapatkan dari luar kelompok tani. Tenaga kerja yang digunakan adalah tenaga kerja yang berasal dari Kelompok Tani tersebut dengan upah Rp 60.000/HOK. Bahan operasional yang dimaksud dalam pembuatan rengginang adalah biaya bahan bakar yang digunakan untuk mengolah rengginang sedangkan biaya penyusutan alat adalah biaya penyusutan dari semua alat yang digunakan dalam agroindustri usaha rengginang.

Harga pokok produksi agroindustri usaha keripik pada kelompok Tani

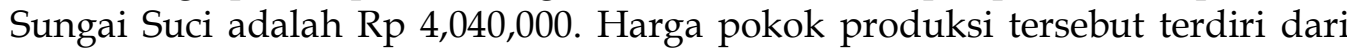
bahan baku Rp 2.240.000, upah tenaga kerja Rp 1.800.000, biaya overhead pabrik yang terdiri dari biaya operasional sebesar $\mathrm{Rp} 40.000$ dan biaya penyusutan peralatan sebesar Rp 24.795. Bahan baku yang digunakan untuk agroindustri usaha keripik adalah ubi kayu segar yang didapat langsung dari anggota Kelompok Tani itu sendiri sedangkan bahan penolong dalam agroindustri usaha keripik ini tidak digunakan, karena dalam pengolahan agroindustri usaha keipik tidak membutuhkan bahan penolong. Tenaga kerja yang digunakan dalam proses agroindustri ini berasal dari dalam Kelompok Tani tersebut. Biaya operasional dalam agroindustri usaha keripik ini digunakan untuk biaya bahan bakar sedangkan biaya penyusutan alat yang dimaksud dalam agroindustri ini adalah biaya penyusutan dari semua peralatan yang digunakan dalam agroindustri usaha keripik pada kelompok Tani Sungai suci.

Agroindustri usaha tepung mocaf pada Kelompok Tani Sungai Suci setiap bulan menghasilkan penjualan sebesar Rp 4.160 .000 dan harga pokok penjualan sebesar Rp 2.419.900, yang didapat dari pengurangan persediaan barang untuk dijual dengan persediaan barang akhir. Dengan mengetahui besarnya penjualan dan persediaan barang jadi akhir maka akan diketahui laba kotor dengan cara mengurangkan penjualan terhadap harga pokok penjualan. Besarnya laba kotor agroindustri usaha tepung mocaf pada Kelompok Tani Sungai Suci setiap bulan sebesar Rp 1.740.100. Untuk mendapatkan laba bersih maka laba kotor dikurangkan dengan biaya penjualan sebesar Rp 32.600 dan biaya administrasi Rp 0. Laba bersih agroindustri usaha tepung mocaf pada Kelompok Tani Sungai Suci setiap bulan adalah Rp 1.707.500. 
ISSN: $1412-8837$

Tabel 4. Perhitungan Rugi/Laba Agroindustri Ubi Kayu Pada Kelompok Tani Sungai Suci

\begin{tabular}{lrrr}
\hline \multicolumn{1}{c}{ Uraian } & $\begin{array}{c}\text { Tepung } \\
\text { Mocaf }\end{array}$ & Rengginang & Keripik \\
\hline Penjualan (a) & 4.160 .000 & 4.500 .000 & 6.750 .000 \\
Harga pokok penjualan: & & & \\
Persediaan barang jadi awal (b) & 0 & 0 & 0 \\
Harga pokok produksi (c) & 2.419 .900 & 2.652 .507 & 4.040 .000 \\
Persediaan barang untuk dijual (d) & 2.419 .900 & 2.652 .507 & 4.040 .000 \\
Persediaan barang jadi akhir (e) & 0 & 0 & 0 \\
Harga pokok penjualan (f=d-e) & 2.419 .900 & 2.652 .507 & 4.040 .000 \\
Laba kotor (g=a-f) & 1.740 .100 & 1.847 .493 & 2.710 .000 \\
Biaya penjualan (h) & 32.600 & 196.800 & 196.600 \\
Biaya administrasi (i) & 0 & 0 & 0 \\
\hline Laba bersih (j=g-(h+i)) & $\mathbf{1 . 7 0 7 . 5 0 0}$ & $\mathbf{1 . 6 5 0 . 6 9 3}$ & $\mathbf{2 . 5 1 3 . 4 0 0}$ \\
\hline
\end{tabular}

Sumber: Data primer diolah, 2016

Agroindustri usaha rengginang pada Kelompok Tani Sungai Suci setiap bulan menghasilkan penjualan sebesar $\mathrm{Rp} 4.500 .000$ dan harga pokok penjualan sebesar Rp 2.652.507 yang didapatkan dari pengurangan persediaan barang jadi dengan persediaan barang akhir. Penjualan dan harga pokok penjualan digunakan untuk mendapatkan atau mencari laba kotor agroindustri usaha rengginang pada kelompok Tani Sungai Suci. Laba kotor didapatkan dengan mengurangkan penjualan terhadap harga pokok penjualan, maka didapat laba kotor agroindustri usaha rengginang pada kelompok Tani Sungai Suci setiap bulan sebesar Rp 1.847.493. Selanjutnya untuk memperoleh laba bersih maka laba kotor dikurangkan dengan biaya penjualan sebesar Rp 196.800 dan biaya administrasi Rp 0. Laba bersih agroindustri usaha rengginang pada Kelompok Tani Sungai Suci setiap bulan adalah Rp 1.650.693.

Agroindustri usaha keripik pada Kelompok Tani Sungai Suci menghasilkan penjualan setiap bulan sebesar Rp 6.70 .000 dan harga pokok penjualan sebesar Rp 4.040.000 yang didapatkan dari pengurangan persediaan barang dijual terhadap persediaan barang jadi akhir. Selanjutnya untuk mencari laba kotor maka dapat dicari dengan mengurangkan penjualan terhadap harga pokok penjualan. Laba kotor agroindustri usaha keripik pada Kelompok Tani Sungai Suci setiap bulan sebesar Rp 2.710.000. Dengan mengetahui besarnya laba kotor maka jika dikurangkan dengan biaya penjualan sebesar Rp 196.600 dan biaya adminitrasi Rp 0 maka akan didapatkan laba bersih. Laba bersih agroindustri keripik pada Kelompok Tani Sungai Suci setiap bulan adalah Rp 2.513.400.

\section{Efisiensi Usaha Agroindustri Ubi Kayu pada Kelompok Tani Sungai Suci}

Efisensi usaha agroindustri ubi kayu pada Kelompok Tani Sungai Suci dihitung dengan menggunakan analisis B/C Ratio, dan Analisis Break Event 
ISSN: $1412-8837$

Point (BEP). Efisiensi usaha agroindustri ubi kayu pada Kelompok Tani Sungai Suci dapat dilihat pada tabel berikut ini:

Tabel 5. Efisiensi Usaha Agroindustri Ubi Kayu pada Kelompok Tani Sungai Suci

\begin{tabular}{lrrr}
\hline Anaisis & Tepung Mocaf & Rengginang & Keripik \\
\hline B/C Ratio & 0,70 & 0,62 & 0,62 \\
BEP & & & \\
$\checkmark$ BEP Volume (Kg/Bulan) & 302,49 & 106,10 & 448,89 \\
$\checkmark$ BEP Harga (Rp) & $4.654,00$ & $14.736,00$ & $5.387,00$ \\
\hline
\end{tabular}

Sumber: Data primer diolah, 2016

\section{B/C Ratio}

Penelitian menunjukkan nilai $\mathrm{B} / \mathrm{C}$ ratio agroindustri tepung mocaf sebesar 0,70 maka agroindustri usaha tepung mocaf pada Kelompok Tani Sungai Suci layak dikembangkan. Begitu juga dengan agroindustri usaha rengginang dan usaha keripik pada Kelompok Tani Sungai Suci layak dikembangkan karena kedua usaha ini masing-masing memiliki nilai B/C ratio sebesar 0,62 dan 0,62 .

Jika dilihat dari nilai $\mathrm{B} / \mathrm{C}$ ratio yang paling besar, maka agroindustri usaha tepung mocaf menjadi agroindustri yang memiliki nilai B/C Ratio yang paling tinggi dari semua usaha agroindustri yang dikelola Kelompok Tani Sungai Suci. Dengan demikian Agroindustri tepung mocaf jika dikembangkan akan memiliki keuntungan yang paling tinggi dibandingkan agroindustri usaha rengginang dan keripik.

\section{Break Event Point (BEP)}

BEP volume didapat dari nilai harga pokok produksi dibagi dengan harga produk. Untuk BEP volume agroindustri usaha tepung mocaf adalah $302.49 \mathrm{~kg} /$ bulan, rengginang 106,10 kg/bulan, dan keripik 448,89 kg/bulan. Pada hasil penelitian setiap bulan Kelompok Tani Sungai Suci memproduksi tepung mocaf sebanyak $400 \mathrm{Kg}$, rengginang $180 \mathrm{Kg}$, dan keripik sebanyak 750 Kg. Kelompok Tani Sungai Suci memproduksi tepung mocaf, rengginang, dan keripik dengan jumlah yang lebih banyak dari jumlah BEP Volume dari setiap usaha artinya jumlah produksinya sudah efisien. BEP harga didapat dari nilai harga pokok produksi dibagi dengan total produksi. Untuk BEP harga agroindustri usaha tepung mocaf adalah Rp 4.654, rengginang Rp 14.736, dan keripik Rp 5.387. Pada hasil penelitian Kelompok Tani menetapkan harga tepung mocaf Rp 8.000, rengginang Rp 25..000, dan keripik Rp 9.000, harga yang ditetapkan Kelompok Tani sungai Suci lebih besar dari BEP artinya harga setiap produk agroindustri sudah efisien.

232 | Yesko Crismas S., Putri Suci A., dan Apri A., Kajian Sistem Agribisnis... 
Subsistem Pemasaran Ubi Kayu dan Hasil Agroindustri Ubi Kayu Pada Kelompok Tani Sungai Suci

Alur Pemasaran Ubi Kayu dan Hasil Agroindustri Ubi Kayu Pada Kelompok Tani Sungai Suci

Ubi kayu sampai ketangan konsumen melalui tingkat rantai pemasaran. Dari petani produsen/Kelompok dijual kepada pedagang pengumpul tingkat desa, selanjutnya pedagang pengumpul tingkat desa menjualnya kepada konsumen perajin olahan ubi kayu. Petani produsen/Kelompok Tani Sungai Suci tidak perlu membawa ubi kayu ke pasar karena pedagang pengumpul tingkat desa ubi kayu medatangi langsung petani produsen ubi kayu dan membelinya dilakukan dilahan petani produsen ubi kayu dengan biaya panen ditanggung oleh pedagang pengumpul tingkat desa. Pedagang pengumpul tingkat desa menjual ubi kayu kepada perajin olahan ubi kayu di rumah pedagang pengumpul tingkat desa tersebut. Ubi kayu dijual setelah dikupas oleh pedagang pengumpul tingkat desa. Untuk lebih jelasnya alur pemasaran ubi kayu pada Kelompok Tani Sungai Suci adalah sebagai berikut:

I. Petani $\rightarrow$ Agroindustri usaha tepung mocaf Kelompok Tani Sungai Suci

II. Petani $\rightarrow$ Pedagang pengumpul tingkat desa $\rightarrow$ Konsumen perajin olahan ubi kayu

Hasil agroindustri tepung mocaf dipasarkan langsung ketangan konsumen tanpa melalui lembaga pemasaran. Tepung mocaf sebagian besar dijual kepada konsumen perajin kue dari tepung mocaf dan sebagian lagi dijual kepada konsumen rumah tangga. Pembeli tepung mocaf membeli langsung ke tempat agroindustri ubi kayu Kelompok Tani Sungai Suci dengan biaya angkut atau ongkos ditanggung oleh pembeli. Selain dijual kepada konsumen tepung mocaf juga dijadikan bahan baku untuk agroindustri usaha rengginang yang dikelola Kelompok Tani Sungai Suci. Hasil agroindustri rengginang dipasarkan kepada konsumen melalui pedagang pengecer yang berada di Pasar Minggu Kota Bengkulu. Pemasaran rengginang dan keripik dilakukan dengan cara Kelompok tani membawa rengginang dan keripik ke pasar dengan biaya ongkos ditanggung oleh Kelompok Tani Sungai Suci. Untuk lebih jelas alur pemasaran hasil agroindustri ubi kayu pada Kelompok Tani Sungai Suci adalah sebagai berikut:

I. Kelompok Tani (tepung mocaf) $\rightarrow$ Konsumen perajin kue dan rumah tangga

II. Kelompok Tani (Rengginang \& Keripik) $\rightarrow$ Konsumen rumah tangga

III.Kelompok Tani (rengginang \&Keripik) $\rightarrow$ Pedagang pengecer $\rightarrow$ Konsumen

\section{Subsistem Lembaga Penunjang Pada Kelompok Tani Sungai Suci}

Lembaga penunjang sistem agribisnis ubi kayu pada Kelompok Tani Sungai Suci adalah Koperasi Wanita Tani Sungai Suci dan Pemerintah. 


\section{Sistem Agribisnis Ubi Kayu Pada Kelompok Tani Sungai Suci}

Sistem Agribisnis ubi kayu yang ada pada Kelompok Tani Sungai Suci terdiri dari subsistem sarana produksi, subsistem usahatani, subsistem agroindustri, subsistem pemasaran, dan subsistem lembaga penunjang. Subsistem-subsistem ini saling berkaitan agar tercipta sistem agribinis ubi kayu yang baik. Sistem agribisnis ubi kayu pada Kelompok Tani Sungai Suci dapat dilihat pada gambar berikut ini:

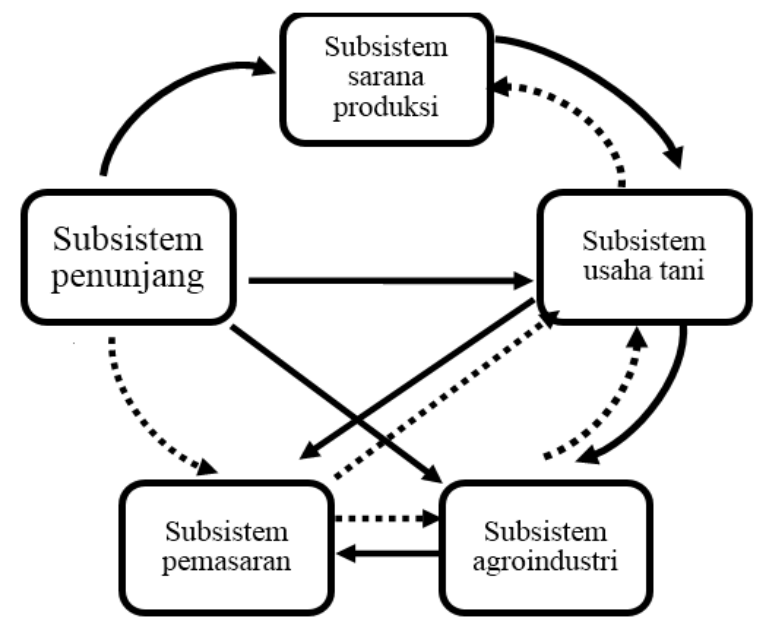

Gambar 6. Sistem agribisnis ubi kayu pada Kelompok Tani Sungai Suci.

Subsistem sarana produksi memberikan sarana produksi kepada subsistem usahatani yaitu berupa bibit, pupuk, mesin pertanian, dan tenaga kerja sedangkan subsistem usahatani memberikan informasi sarana produksi apa saja yang dibutuhkan dalam subsistem usahatani. Selanjutnya subsistem usahatani memberikan komoditi kepada subsistem agroindustri untuk dijadikan bahan baku sedangkan subsistem agroindustri memberikan informasi kepada subsistem usahatani tentang bahan baku yang akan digunakan dalam subsistem agroindustri. Subsistem usahatani dan subsistem agroindustri memberikan komoditi kepada subsistem pemasaran sedangkan subsistem pemasaran memberikan informasi kepada subsistem usahatani tentang ubi kayu yang diminta oleh konsumen dan memberikan informasi kepada subsistem agroindustri tentang hasil olahan ubi kayu yang diinginkan oleh konsumen.

\section{SIMPULAN DAN SARAN}

\section{Simpulan}

Berdasarkan hasil penelitian kajian sistem agribisnis ubi kayu pada Kelompok Tani Sungai Suci dapat diambil kesimpulan sebagai berikut: 
1. Subsistem sarana produksi yang ada di Kelompok Tani Sungai Suci adalah unit usaha penyediaan bibit, unit usaha penyediaan pupuk, unit usaha penyediaan mesin pertaniaan, dan unit usaha tenaga kerja.

2. Rata-rata pendapatan rill per Ha usahatani ubi kayu pada Kelompok Tani Sungai Suci adalah Rp 18.681.033 sedangkan rata-rata pendapatan unrill per Ha adalah Rp 12.626.045.

3. Laba bersih per bulan agroindustri ubi kayu pada Kelompok Tani Sungai Suci adalah pengolahan tepung mocaf sebesar Rp 1.707.500, Pengolahan rengginang sebesar $R p$ 1.650.693, dan pengolahan keripik sebesar Rp 2 . 513.400

4. Ada dua jenis saluran dalam sistem agribisnis ubi kayu Kelompok Tani Sungai Suci.

Pertama Saluran Pemasaran ubi kayu:

I. Petani $\rightarrow$ Agroindustri ubi kayu $\rightarrow$ Kelompok Tani Sungai Suci

II. Petani $\rightarrow$ Pedagang pengumpul tingkat desa $\rightarrow$ Konsumen perajin olahan ubi kayu

Kedua adalah saluran pemasaran hasil agroindustri ubi kayu:

I. Kelompok Tani Sungai Suci (tepung mocaf) $\rightarrow$ Konsumen perajin kue dan rumah tangga

II. Kelompok Tani Sungai Suci (Rengginang \& keripik) $\rightarrow$ Konsumen rumah tangga

III.Kelompok Tani Sungai Suci (Rengginang \& Keripik) $\rightarrow$ Pedagang pengecer $\rightarrow$ Konsumen

5. Lembaga yang berperan sebagai subsistem penunjang dalam sistem agribisnis ubi kayu Kelompok Tani Sungai Suci adalah Koperasi Wanita Tani Sungai Suci dan Pemerintah. Koperasi Wanita Tani Sungai Suci menunjang subsistem sarana produksi, subsistem usahatani, dan subsistem agroindustri dalam meminjamkan modal dan menunjang subsistem pemasaran dengan cara mempromosikan hasil agroindustri. Pemerintah menunjang sistem agribisnis ubi kayu dengan memberikan bantuan modal sarana produksi, mesin pertanian untuk usahatani, mesin pengiris dan penepung untuk agroindustri dan mempromosikan hasil agroindustri ubi kayu Kelompok Tani Sungai Suci.

\section{Saran}

Berdasarkan hasil penelitian kajian sistem agribisnis ubi kayu pada Kelompok Tani Sungai Suci maka disarankan:

1. Kelompok Tani Sungai Suci Diharapkan mampu menyediakan sarana produksi pestisida dan alat pertanian guna mempermudah anggota Kelompok Tani dalam usahatani ubi kayu.

2. Perlu dilakukan promosi produk hasil agroindustri secara terus-menerus hingga produk hasil agroindustri dikenal oleh banyak orang.

3. Meningkatkan kuantitas produksi agroindustri karena pada efisiensi usaha, agroindustri ubi kayu pengolahan tepung mocaf, rengginang, dan keripik layak dikembangkan. 


\section{DAFTAR PUSTAKA}

Muizah, dkk. 2013. Analisis Pendapatan Usahatani. Ubi Kayu (Manihot Esculenta Crantz) (Studi Kasus Desa mojo Kecamatan Cluwak Kabupaten Pati). Mediagro Vol. 9. Surakarta.

Soekartawi. 2002. Analisis Usahatani. UI - Press. Jakarta.

Soemarso. 1999. Pengantar Akuntansi I. Cetakan Kesembilan, PT Rineka Cipta. Jakarta.

Suratiyah, Ken. 2008. Ilmu Usahatani. Penebar Swadaya. Jakarta.

Thamrin, dkk. 2013. Analisis Usahatani Ubi Kayu (Manihot utilissima). Agrium Vol. 18. Medan.

Wiryanta. 2002 Diacu dalam Marissa. 2010. Analisi Pendapatan Usahatani Tebu (Studi Kasus: PT. PG Rajawali Unit PG Tersana Baru, Babakan, Cirebon, Jawa Barat).UIN. Jakarta. 